\title{
The paca that roared
}

Oppenheim, Gary

\section{Cognition}

\author{
DOI: \\ 10.1016/j.cognition.2018.02.014
}

Published: 01/08/2018

Peer reviewed version

Cyswllt i'r cyhoeddiad / Link to publication

Dyfyniad o'r fersiwn a gyhoeddwyd / Citation for published version (APA):

Oppenheim, G. (2018). The paca that roared: Immediate cumulative semantic interference among newly acquired words. Cognition, 177(August), 21-29.

https://doi.org/10.1016/j.cognition.2018.02.014

\footnotetext{
Hawliau Cyffredinol / General rights

Copyright and moral rights for the publications made accessible in the public portal are retained by the authors and/or other copyright owners and it is a condition of accessing publications that users recognise and abide by the legal requirements associated with these rights.

- Users may download and print one copy of any publication from the public portal for the purpose of private study or research.

- You may not further distribute the material or use it for any profit-making activity or commercial gain

- You may freely distribute the URL identifying the publication in the public portal ?
}

Take down policy

If you believe that this document breaches copyright please contact us providing details, and we will remove access to the work immediately and investigate your claim. 
Running head: THE PACA THAT ROARED

Word Count: 2998, including main body text, abstract, headers, and tables, but not figure captions, reference listing, or title page.

The paca that roared: immediate cumulative semantic interference among newly acquired words

Gary M. Oppenheim

School of Psychology, Bangor University

Department of Psychology, Rice University

Author note

Correspondence concerning this article should be addressed to Gary M. Oppenheim, School of Psychology, Bangor University, Adeilad Brigantia, Bangor, Gwynedd, LL57 2AS, UK. Electronic mail may be sent to g.m.oppenheim@bangor.ac.uk. Experimental materials are available upon request. 


\begin{abstract}
With 40,000 words in the average vocabulary, how can speakers find the specific words that they want so quickly and easily? Cumulative semantic interference in language production provides a clue: when naming a large series of pictures, with a few mammals sprinkled about, naming each subsequent mammal becomes slower and more error-prone. Such interference mirrors predictions from an incremental learning algorithm applied to meaning-driven retrieval from an established vocabulary, suggesting retrieval benefits from a constant, implicit, reoptimization process (Oppenheim, Dell, \& Schwartz, 2010). But how quickly would a new mammal (e.g. paca) engage in this re-optimization? In this experiment, 18 participants studied 3 novel and 3 familiar exemplars from each of six semantic categories, and immediately performed a timed picture-naming task. Consistent with the learning model's prediction, naming latencies revealed immediate cumulative semantic interference in all directions: from new words to new words, from new words to old words, from old words to new words, and from old words to old words. Repeating the procedure several days later produced similar-magnitude effects, demonstrating that newly acquired words can be immediately semantically integrated, at least to the extent necessary to produce typical cumulative semantic interference. These findings extend the Dark Side model's scope to novel word acquisition, and are considered in terms of mechanisms for lexical selection.
\end{abstract}


Introduction

People know a lot of words (e.g. Nagy \& Herman, 1987), but what does it mean to 'know' a word? Is a person's vocabulary merely a static collection of the words that they know, or something more dynamic?

Cumulative semantic interference in picture naming provides a clue: as a person names a series of a hundred pictures, with a few mammals interspersed, each successive mammal becomes persistently harder to name than the previous (e.g. Brown, 1981). This interference accumulates with each semantically related retrieval (Navarrete, Mahon, \& Caramazza, 2010), persists over time and irrelevant experience (Howard, Nickels, Coltheart, \& Cole-Virtue, 2006), and does not require explicit memory for previous exemplars (Oppenheim, Barr, \& Tainturier, 2016), precisely as if an implicit learning algorithm were operating on the task of mapping shared semantic features to individual words in a neural network, incrementally overwriting competing associations (Navarrete et al., 2010; Oppenheim, Dell, \& Schwartz, 2007, 2010): naming a picture of a tiger strengthens the semantic connections that support tiger ([mammal] $\rightarrow$ tiger), and weakens any that erroneously activate its competitors ([mammal] $\rightarrow$ hedgehog), thereby making hedgehog harder to retrieve when cued later. Remarkably, this interference has typically been demonstrated using very well-known words (e.g. tiger, hedgehog), leading to a theoretical claim that speakers continually learn and unlearn even words that they have 'known' for decades (Oppenheim et al., 2010).

If established vocabularies show such plasticity, how quickly would a novel word, like paca (a small burrowing rodent, native to South America) become semantically integrated enough to engage in this re-optimization process? Predictions may depend on the role of online 
competition in determining the timecourse of word retrieval in general, and creating cumulative semantic interference in particular. Oppenheim and colleagues' (2010) Dark Side model, described above, emphasizes error-driven unlearning of competing associations: retrieving paca should weaken the [mammal] $\rightarrow$ hedgehog connection to the extent that it erroneously activates hedgehog, thereby rendering hedgehog harder to retrieve in the future. But other accounts (Abdel Rahman \& Melinger, 2009; Belke, 2013; Howard et al., 2006; Roelofs, 2018) have long assigned online competition a more central role in turning repetition priming or residual activation into semantic interference: hedgehog should grow less accessible only insofar as the nascent paca gets in the way.

A decade of word-learning research offers the general conclusion that novel words can be quickly 'configured' for retrieval — for instance allowing successful picture naming — but require more time, practice, and/or sleep before dynamically engaging with other vocabulary (Leach \& Samuel, 2007). Thus novel words tend not to compete immediately with familiar words, perhaps because their slower and less automatic processing does not activate them in time to do so (Davis \& Gaskell, 2009). Whereas familiar words can be retrieved quickly though strong and direct neocortical mappings, novel words initially depend more on weaker, slower, hippocampal routes. Pattern reinstatement during sleep may consolidate hippocampal traces into neocortical mappings (ibid), or simply strengthen them (Kumaran, Hassabis, \& McClelland, 2016), yielding more efficient retrieval that allows competition effects to emerge. A novel wordform, like cathedruke, therefore typically requires sleep-based consolidation before competing with established phonological neighbors, like cathedral (Gaskell \& Dumay, 2003 et passim), and semantic effects including picture-word interference (Clay, Bowers, Davis, \& Hanley, 2007) have invariably required similar delays (Coutanche \& Thompson-Schill, 2014; Tamminen \& 
Gaskell, 2013; van der Ven, Takashima, Segers, \& Verhoeven, 2015). Therefore, if online competition is central to cumulative semantic interference in production, paca should not impair hedgehog retrieval until after consolidation.

Whether retrieving tiger or yapok (a web-footed Central American marsupial) should interfere with paca similarly depends on theory. The Dark Side model assumes incremental semantic-to-lexical learning and unlearning from the moment a new word is established, implying paca's immediate vulnerability to interference from both. But Complementary Learning Systems theories propose an additional, sparser, means of storing novel associations (hippocampal conjunctive coding), trading semantic richness for representational independence that prevents it from overwriting or being overwritten by other concepts that share its features (e.g. McClelland, McNaughton, \& O’Reilly, 1995). If such sparse storage introduces a sparse route for novel word retrieval-retrieving paca via its conjunctive code instead of shared semantic features - it could plausibly insulate novel words from both competitive selection (retrieving paca without engaging tiger or yapok) and 'competitive' unlearning (by making paca less dependent on input from the shared [mammal] feature, essentially bypassing the semanticto-lexical mapping). The same mechanism that prevents new memories from catastrophically interfering with old ones may thereby provide an interference-resistant route for retrieving them.

Thus, it is unclear whether or how the scope of an incremental lexical learning model should extend to novel word production. The Dark Side model offers predictions for cumulative semantic interference involving novel words, but they hinge on the uncertain contributions of semantically rich retrieval and competitive lexical selection. Therefore, the current study considers, for the first time, the emergence of a well-studied semantic effect (cumulative semantic interference) as a way to assess this possible extension, consider the cognitive 
mechanisms underlying the behavioral effect, and more generally assess the timecourse of novel words semantic integration.

\section{Method}

\section{Participants}

Eighteen native-English Bangor University students (11 female) received $£ 12$ or course credit for participation. All provided informed consent, reporting and normal or corrected-tonormal vision and hearing. Additional participants were replaced due to technical difficulties (2), excessive omissions (>25\%) (3), or prior familiarity with too many novel items (2).

\section{Design}

In a continuous one-hour session, each participant first read a short booklet introducing three novel (e.g. paca, noni) and three familiar (e.g. badger, apple; mean SUBTLEX $\mathrm{UK}_{\mathrm{U}}$ Zipf: 3.91; van Heuven, Mandera, Keuleers, \& Brysbaert, 2013) disyllabic real-word exemplars of six semantic categories (e.g. mammals, fruits). They then completed two card-sorting training tasks, rated their prior familiarity with each exemplar, and finally completed the timed picture naming testing task. Pseudorandom trial orders for picture naming allowed estimating semantic interference from novel and familiar category coordinates, plus generalized slowing, as minimally collinear within-items/subjects effects. To assess consolidation-dependent changes, the protocol was repeated 1-7 days later $(\mathrm{M}=46.0$ hours, $\mathrm{SD}=36.6)$. 


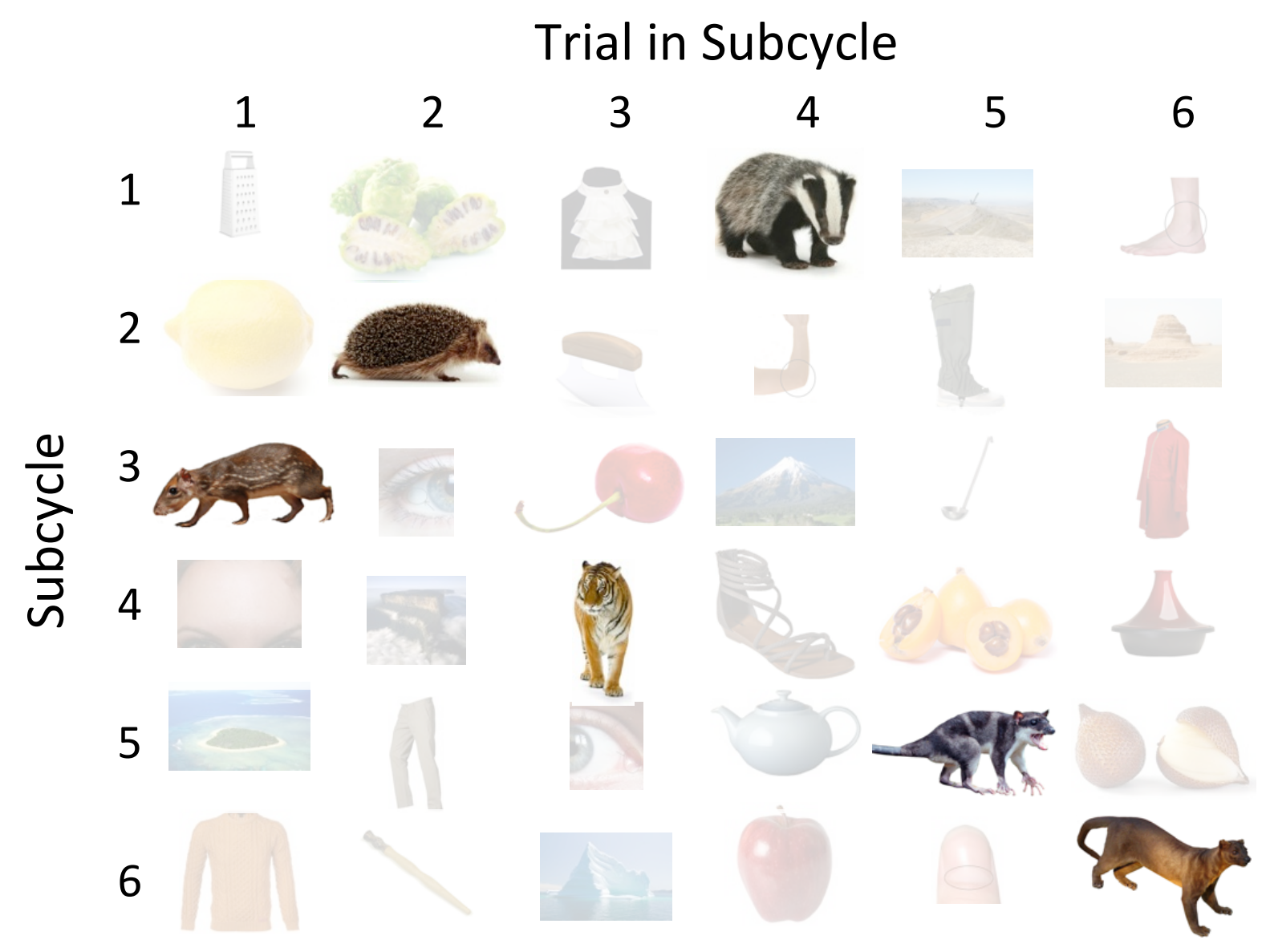

Figure 1. One example cycle from the naming task, highlighting the mammal exemplars \{badger (familiar), hedgehog (familiar), paca (novel), tiger (familiar), yapok (novel), fossa (novel)\}. The familiar mammal tiger appears as the third trial in its subcycle, and this linear effect indexes simple decay or nonsemantic interference. Because it is a familiar mammal and two familiar mammals $\{$ badger, hedgehog $\}$ precede it, its Ordinal Position within Novelty is 3 , and because one novel mammal $\{\mathrm{paca}\}$ precedes it, its Ordinal Position ${ }_{\text {between } \text { Novelty }}$ is 1 . By contrast, the novel paca appears as the first trial in its subcycle; because it is a novel mammal and no novel mammals precede it in this cycle, paca's Ordinal Position ${ }_{\text {within Novely }}$ is 1, and because two familiar mammals precede it, its Ordinal Position between Novelty $_{\text {is }} 2$. 
Introduction booklet (training). Each page introduced one novel or familiar exemplar, including three color photographs (selected from the internet) to establish view-invariant visuospatial representations and three one-sentence facts (e.g. "Pacas dig burrows for shelter and protection,"). Participants studied this 36-item booklet for ten minutes.

Cardsorting (training). The same $36 * 3$ photographs then served as the bases for two rounds of word-to-picture and picture-to-word speeded cardsorting. Each card showed a photograph on one side and its name on the other. In the word-to-picture task, participants sorted 108 randomized word-side-up flashcards onto a grid of pictures, naming each in the process; time-pressure encouraged memorization. An analogous picture-to-word task matched pictureside-up cards to the word grid. Within the picture or word grid, each (unlabeled) column contained randomly arranged exemplars of a single category, providing shared affordances analogous to real-world category use. Five minutes were allowed for Round 1, four minutes for Round 2; anyone exceeding the four-minute deadline repeated the tasks as Round 3.

Novelty ratings. In this 36-trial E-Prime-based task, participants saw one photograph of each item, with its name below, rating it on a seven-point scale from "I use this word at least once a week" to "I had never encountered this word before this experiment."

Timed picture naming (testing). The same 36 photographs now served as stimuli for a pseudorandomly ordered $36 * 6=216$-trial E-Prime-based timed picture naming task. Participants were instructed to quickly and accurately name each picture, avoiding omissions. Each trial presented a 500ms blank screen, 500ms fixation, 500ms blank screen, and then a centered color photograph for $2500 \mathrm{~ms}$ or until the 50ms-delayed-threshold voicekey (Tyler, Tyler, \& Burnham, $2005)$ triggered; the desired name then appeared below for $700 \mathrm{~ms}$ as feedback. Vocalizations were digitally recorded via a headmounted microphone, and transcribed offline. 
Eighteen counterbalanced lists optimized the picture orders for subsequent analyses. In each list, 6x36-trial 'Cycles' each included one photograph of each exemplar (Figure 1); each exemplar appeared once in each within-category ordinal position (e.g. as the fifth mammal). In each Cycle, 6x6-trial 'Subcycles' contained one exemplar from each semantic category (three novel, three familiar), interleaving all exemplars, categories, and novelty levels. Across lists, exemplars appeared equally in each 'Ordinal Position within Novelty level', and with constant proportions in each 'Ordinal Position between Novelty levels', allowing separate estimation of interference from novel and familiar exemplars. Each item also appeared equally in each 'Trial in Subcycle' position, allowing estimation of decay or non-semantic interference.

Analyses

To ensure the novelty of novel exemplars, data from any that a participant failed to rate as completely novel (Appendix A) was discarded, unless its Session 1 accuracy was at or below their confirmed-novel items ${ }^{1}$, excluding approximately two exemplars per participant.

Picture naming responses were classified as: a) correct, b) errors, or c) voicekey misfires; visual waveform analyses corrected late voicekey triggers.

Preplanned lme4 mixed effects regressions included centered linear fixed effects for Session (1:2), Cycle (1:6), Novelty (familiar, novel), Trial in Subcycle (1:6), Ordinal position ${ }_{\text {within }}$ Novelty (1:3; novel-to-novel and familiar-to-familiar interference), and Ordinal position between Novelty $_{\text {. }}$ (0:3; novel-to-familiar and familiar-to-novel interference), plus two- and three-way interactions between Session and Novelty and all other variables. For errors, logistic regressions included random intercepts for participants and items, but no random slopes due to data sparseness. For

\footnotetext{
${ }^{1}$ Several participants voiced concern over miskeying subsets of their novelty ratings.
} 
naming latencies, linear mixed effects regressions analysed inverse-transformed RTs (100000/RT optimized normality of residuals, e.g. Baayen, 2008, but untransformed RTs yield similar results) and included maximal random effects (Barr, Levy, Scheepers, \& Tily, 2013) for participants and items, omitting correlations to facilitate convergence, plus per-category random slopes for Novelty and its interactions. Naming latency analyses included only correct, correctly detected responses; any trial immediately following an error was also excluded to avoid posterror slowing (Rabbitt, 1966), but including them yields similar results. After initial fitting, observations with absolute standardized residuals $>2.5$ were removed as influential points, and the model refit (e.g. Baayen \& Milin, 2010). Treating t-statistics as z-scores yields nondirectional p-values. Betas include Wald confidence intervals. Simple main effects describe identical procedures and predictors applied to restricted datasets. Full regression tables are given in the appendices.

\section{Results/Discussion}

Errors.

Participants generated 412 naming errors, detailed in Appendix B. Notably, these contained 124 word errors (Session 1: 94; Session 2: 28) where a participant named a novel exemplar using the name of a category coordinate, versus only 22 (Session 1: 18; Session 2: 4) cross-category errors, suggesting immediate semantic influences. Novel exemplars were particularly error-prone in Session 1 (total errors: Session: $\beta=-2.10 \pm 0.32, \mathrm{p}<.001$ ), where the benefits of repetition (Cycle: $\beta=-0.28 \pm 0.09, \mathrm{p}<.001)$ were greater (Session*Cycle: $\beta=0.18 \pm 0.18$, $\mathrm{p}=.047)$. They also grew increasingly error-prone after naming other novel exemplars from the 
same category (Ordinal position within Novelty $_{\beta} \beta=0.25 \pm 0.20, \mathrm{p}=.015$ ), one manifestation of cumulative semantic interference. No other novel-target error effects approached significance (all p>.15), and the 40 familiar-target errors provide insufficient bases for detailed analyses.

\section{Naming latencies}

Excluding errors left 2931 confirmed-novel (75.4\%; 1298 in Session 1; 1633 in Session 2) and 3559 familiar $(91.5 \%$; 1698 in Session 1; 1861 in Session 2) trials for the naming latency analyses (Pearson's $r=.805$ ). Unsurprisingly, novel items were slower than familiar (Novelty: $\beta=38.6 \pm 8.8, p<.001)$, but improved more with each repetition $($ Cycle: $\beta=-0.645 \pm 0.668, p=.058$; Novelty x Cycle: $\beta=-2.59 \pm 0.59, \mathrm{p}<.001)$ and improved more across sessions (Session: $\beta=-$ $8.20 \pm 3.89, \mathrm{p}<.001$; Novelty $x$ Session: $\beta=-15.7 \pm 3.9, \mathrm{p}<.001)$, consistent with a general strengthening role for consolidation.

But novel and familiar naming latencies otherwise patterned similarly (Figure 2), both immediately showing cumulative semantic interference (Ordinal position within Novelty $: \beta=2.32 \pm 0.83$, $\mathrm{p}<.001$; Ordinal position within Novelty $\mathrm{x}$ Novelty: $\beta=0.257 \pm 1.383, \mathrm{p}=.34$; Ordinal position $_{\text {between Novelty: }}$ : $\beta=1.61 \pm 0.44, p<.001 ;$ Ordinal position between Novelty $x$ Novelty: $\beta=0.846 \pm 0.878, p=.059)$ that remained stable across sessions (Ordinal position ${ }_{\text {within Novelty }} \times$ Session: $\beta=0.611 \pm 1.257, p=.34$; Ordinal position ${ }_{\text {between Novelty }} \times$ Session: $\left.\beta=-0.232 \pm 0.811, \mathrm{p}=.57\right)$. Regressions fit to restricted subsets confirm that familiar words showed interference from other familiar words (Figure 2a; Session 1: $\beta=1.69 \pm 1.63, \mathrm{p}=.043$; Session $2: \beta=2.68 \pm 1.32, \mathrm{p}<.001)$, and also immediately showed semantic interference from novel words (Figure 2b; Session 1: $\beta=1.33 \pm 1.10, p=.018$; Session 2: $\beta=1.04 \pm 0.84, p=.015)$. Semantic interference effects on novel word latencies were similarly 
robust, from both novel (Figure 2a; Session 1: $\beta=2.66 \pm 1.46$, $\mathrm{p}<.001$; Session 2: $\beta=2.42 \pm 1.36$, $\mathrm{p}<.001$ ) and familiar category coordinates (Figure $2 \mathrm{~b}$; Session $1: \beta=2.19 \pm 0.94, \mathrm{p}<.001$; Session 2: $\beta=1.94 \pm 0.72, p<.001)$. Thus, cumulative semantic interference appeared immediately and remained stable thereafter.
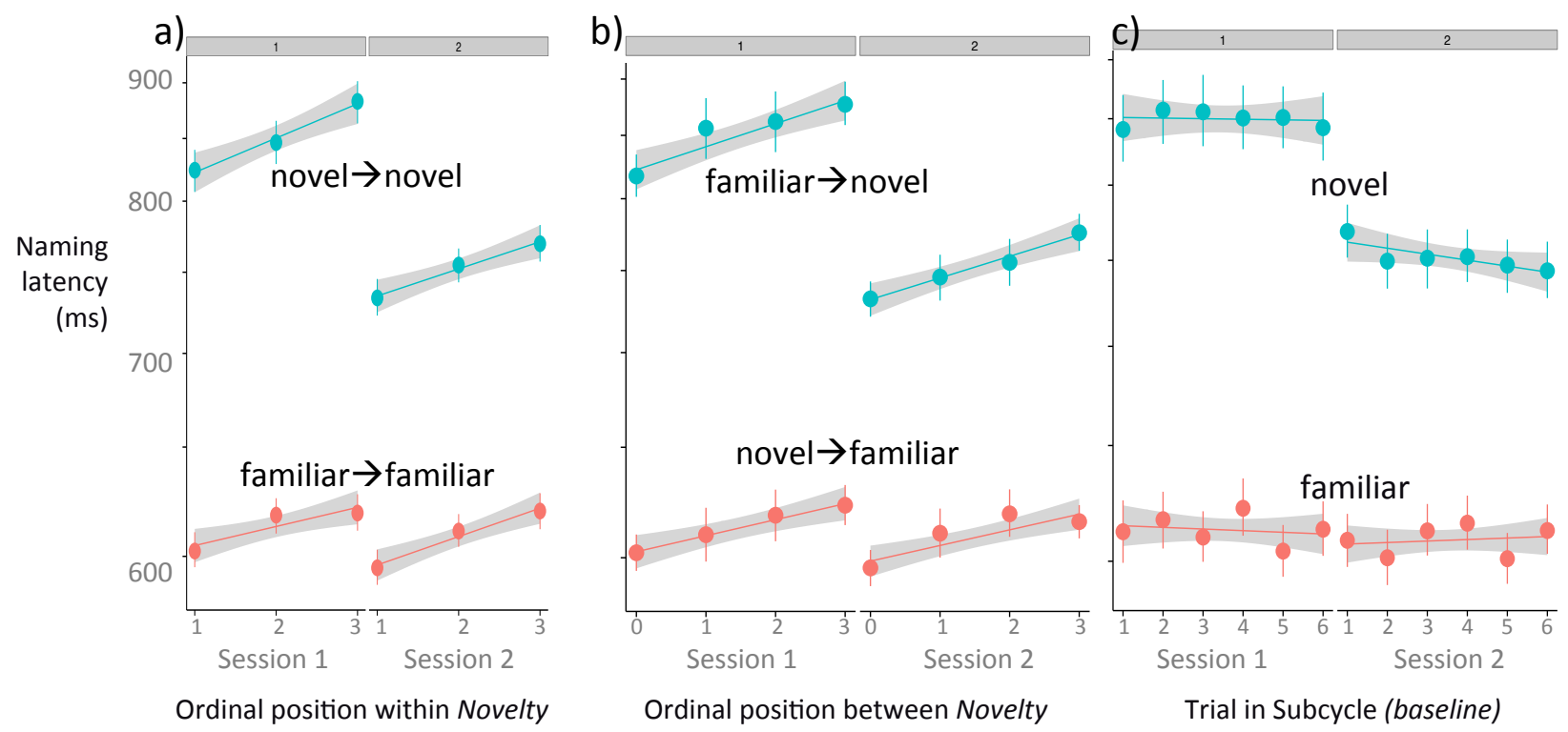

Figure 2. Naming latencies for novel words immediately create and are affected by cumulative semantic interference in Session 1, and these effects appear unchanged by consolidation in Session 2. Panel a: Novel words immediately show cumulative semantic interference from other novel words, and familiar words immediately show cumulative semantic interference from other familiar words. Panel b: Novel words immediately show cumulative semantic interference from familiar words, and familiar words immediately show cumulative semantic interference from novel words. Panel c: Neither novel nor familiar words show any general slowing in either session, reinforcing the characterization of the slowing in Panels a and $b$ as cumulative semantic interference. Latencies are plotted on the same inverse-transformed scale as the regression analyses. Error bars and shading depict $95 \%$ point and slope confidence intervals, respectively. 
If these "semantic" interference measures were merely mischaracterizing decay, nonsemantic interference, or mere association, then intervening time and trials should make pictures named later in a subcycle slower than those named earlier. But naming latencies showed the opposite trend (Figure 2c), nonsignificantly decreasing within each subcycle (Trial in Subcycle: $\beta=-0.285 \pm 0.374, p=.14$ ), a trend that differs neither as a function of novelty (Trial in Subcycle $x$ Novelty: $\beta=-0.182 \pm 0.818, p=.66$ ) nor consolidation (Trial in Subcycle $x$ Session: $\beta=-$ $0.061 \pm 0.709, p=.87$; Trial in Subcycle $x$ Novelty $x$ Session: $\beta=-0.166 \pm 1.230, p=.79)$. Thus, the observed interference is specifically semantic.

No other effects approached significance (ps>.3).

\section{General Discussion}

This study was motivated by a prediction derived from the Dark Side model of incremental word learning (Oppenheim et al., 2010), regarding the development of cumulative semantic interference involving novel words. Timed picture naming revealed cumulative semantic interference, not just from familiar words to familiar words, but from novel to familiar words, familiar to novel words, and novel to novel words. Confirming the model's basic predictions, all effects emerged immediately within the first session, and none detectably increased after an opportunity for sleep-based consolidation.

Accounts of novel word learning typically distinguish between rapid acquisition that can support accurate retrieval and more gradual integration that underlies online priming and competition in both comprehension (Davis \& Gaskell, 2009; Leach \& Samuel, 2007) and production (Clay et al., 2007). In this context, the immediacy and stability of cumulative 
semantic interference is more consistent with an unlearning-based effect than one that crucially depends on competition. This point is particularly clear when considering the necessary scaffolding for paca to interfere with tiger. According to competition-centric accounts, paca would need to at least be strongly activated at the same time as tiger (Belke, 2013; Roelofs, 2018), perhaps having developed a network of lateral inhibitory links (Howard et al., 2006). But the Dark Side model's unlearning account requires much less. Although it is fully compatible with both online competition and consolidation ${ }^{2}$, the model's fundamental claim is simply that each time a speaker uses a shared semantic feature to access a word - novel or familiar — they reweight the connections from that feature to more efficiently retrieve that word in the future. So, to the extent that speakers retrieve novel words via features shared with established words, the model predicts that retrieving them should create (and reflect) the same cumulative semantic interference as established words, and this study confirms that they do.

But beyond interfering with tiger, paca was also immediately vulnerable to interference from tiger and yapok. Following the Dark Side model's assumption that cumulative semantic interference among familiar words chiefly reflects neocortical implicit learning, similar interference among novel words suggests that even their early retrieval similarly depends on such semantically rich neocortical mappings, thus expanding the models scope. ${ }^{3}$ In other words, although sparse hippocampal representation may provide interference-resistant storage for novel words, it does not seem to provide an interference-resistant route for their retrieval.

\footnotetext{
${ }^{2}$ For instance, stochastically reinstating related patterns may help avoid catastrophic interference.

${ }^{3}$ Another explanation - that cumulative semantic interference among familiar words typically reflects hippocampal episodic memory (de Zubicaray, Johnson, Howard, \& McMahon, 2014) - can be quickly discounted because it is undiminished by hippocampal damage (Oppenheim et al., 2016).
} 
Thus, the current results may reflect a form of rapid lexical integration, at least insofar as novel word retrieval depends on shared semantic representations. Although considerable research has demonstrated an important role for sleep-based consolidation in novel word learning, other studies have recently claimed evidence of rapid integration, such as novel wordforms immediately priming phonological neighbors (e.g. Coutanche \& Thompson-Schill, 2014). Within general CLST, such instances are typically attributed to an ease of integrating schema-consistent information within existing neocortical networks (McClelland, 2013). Behavioral evidence in word learning has remained limited to form-based associations, though. Semantic associations have always required delays (Coutanche \& Thompson-Schill, 2014; Tamminen \& Gaskell, 2013; van der Ven et al., 2015; but see Borovsky, Kutas, \& Elman, 2010 et passim for ERP evidence that their neural bases may emerge sooner), and this distinction notably includes Clay and colleagues' (2007) finding that novel words created semantic pictureword interference for familiar words, but only after a one-week delay. Thus, if cumulative semantic interference can be said to require lexical-semantic integration, this would be the first ${ }^{4}$ study demonstrating that semantic word representations can be integrated with similar alacrity.

\section{Conclusion}

This study has considered the emergence of a well-established, but continually controversial, semantic effect in the course of novel word learning, demonstrating that it emerges immediately when acquiring novel words. Considering previous demonstrations that lexical competition effects tend require consolidation-based delays, the quick emergence of cumulative

\footnotetext{
${ }^{4}$ My lab has since replicated these results with simplified training methods (Alzahrani, 2017), demonstrating that, if this rapid semantic integration is unusual, it is nonetheless replicable.
} 
semantic interference is most consistent with the idea that it reflects the implicit strengthening and weakening of semantic-to-lexical connections that incrementally re-tunes access to established words throughout the lifespan, and that these processes operate on old and new words alike. More generally these results illustrate how the mind constantly and rapidly adapts to changing probabilities and new possibilities. In the case of meaning driven word production, this plasticity means that novel words can be semantically integrated with both novel and existing vocabulary, immediately. 


\section{Acknowledgements}

Thanks to Adam Davies, Tessa Mann, Nick McCullough, and Katie O'Rourke for assistance with a pilot study, and to Ryan Flynn for partial data collection for the current study. Thanks also to Gary Dell, Jay McClelland, Jakke Tamminen, Stephan Boehm, Simon FischerBaum, and Randi Martin for comments on this work and other contributions.

\section{References}

Abdel Rahman, R., \& Melinger, A. (2009). Semantic context effects in language production: A swinging lexical network proposal and a review. Language and Cognitive Processes, 24(5), 713-734. http://doi.org/10.1080/01690960802597250

Alzahrani, S. (2017). Novel words: the integration of new words into existing vocabulary (Unpublished masters thesis). Bangor University.

Baayen, R. H. (2008). Analyzing Linguistic Data: A Practical Introduction to Statistics Using $R$. Sociolinguistic Studies (Vol. 2). http://doi.org/10.1558/sols.v2i3.471

Baayen, R. H., \& Milin, P. (2010). Analyzing reaction times. International Journal of Psychological Research, 3(2), 12-28.

Barr, D. J., Levy, R., Scheepers, C., \& Tily, H. J. (2013). Random effects structure for confirmatory hypothesis testing: Keep it maximal. Journal of Memory and Language, 68(3), 255-278. http://doi.org/10.1016/j.jml.2012.11.001

Belke, E. (2013). Long-lasting inhibitory semantic context effects on object naming are necessarily conceptually mediated: Implications for models of lexical-semantic encoding. Journal of Memory and Language, 69(3), 228-256. 
http://doi.org/10.1016/j.jml.2013.05.008

Borovsky, A., Elman, J. L., \& Kutas, M. (2012). Once is Enough: N400 Indexes Semantic Integration of Novel Word Meanings from a Single Exposure in Context. Language Learning and Development, 8(3), 278-302. http://doi.org/10.1080/15475441.2011.614893

Borovsky, A., Kutas, M., \& Elman, J. (2010). Learning to use words: Event-related potentials index single-shot contextual word learning. Cognition, 116(2), 289-296. http://doi.org/10.1016/j.cognition.2010.05.004

Brown, A. S. (1981). Inhibition in cued retrieval. Journal of Experimental Psychology: Human Learning and Memory, 7(3), 204-215. http://doi.org/10.1037/0278-7393.7.3.204

Clay, F., Bowers, J. S., Davis, C. J., \& Hanley, D. a. (2007). Teaching adults new words: the role of practice and consolidation. Journal of Experimental Psychology: Learning, Memory, and Cognition, 33(5), 970-6. http://doi.org/10.1037/0278-7393.33.5.970

Coutanche, M. N., \& Thompson-Schill, S. L. (2014). Fast Mapping Rapidly Integrates Information Into Existing Memory Networks. Journal of Experimental Psychology: General, 143(6), 2296-2303.

Davis, M. H., \& Gaskell, M. G. (2009). A complementary systems account of word learning: neural and behavioural evidence. Philosophical Transactions of the Royal Society of London. Series B, Biological Sciences, 364(1536), 3773-800. http://doi.org/10.1098/rstb.2009.0111

de Zubicaray, G., Johnson, K., Howard, D., \& McMahon, K. (2014). A perfusion fMRI investigation of thematic and categorical context effects in the spoken production of object names. Cortex, 54(1), 135-149. http://doi.org/10.1016/j.cortex.2014.01.018 
Dumay, N., \& Gaskell, M. G. (2007). Sleep-associated changes in the mental representation of spoken words. Psychological Science, 18(1), 35-9. http://doi.org/10.1111/j.14679280.2007.01845.x

Gaskell, M. G., \& Dumay, N. (2003). Lexical competition and the acquisition of novel words. Cognition, 89(2), 105-132. http://doi.org/10.1016/S0010-0277(03)00070-2

Howard, D., Nickels, L., Coltheart, M., \& Cole-Virtue, J. (2006). Cumulative semantic inhibition in picture naming: experimental and computational studies. Cognition, 100(3), 464-82. http://doi.org/10.1016/j.cognition.2005.02.006

Kumaran, D., Hassabis, D., \& McClelland, J. L. (2016). What learning systems do intelligent agents need? Complementary Learning Systems Theory Updated. Trends in Cognitive Sciences, 20(7), 512-534. http://doi.org/10.1016/j.tics.2016.05.004

Leach, L., \& Samuel, A. G. (2007). Lexical configuration and lexical engagement: when adults learn new words. Cognitive Psychology, 55(4), 306-53. http://doi.org/10.1016/j.cogpsych.2007.01.001

McClelland, J. L. (2013). Incorporating rapid neocortical learning of new schema-consistent information into complementary learning systems theory. Journal of Experimental Psychology: General, 142(4), 1190-210. http://doi.org/10.1037/a0033812

McClelland, J. L., McNaughton, B. L., \& O’Reilly, R. C. (1995). Why there are complementary learning systems in the hippocampus and neocortex: Insights from the successes and failures of connectionist models of learning and memory. Psychological Review, 102(3), $419-457$.

Nagy, W. E., \& Herman, P. A. (1987). Breadth and depth of vocabulary knowledge: Implications 
for acquisition and instruction. In M. G. McKeown \& M. E. Curtis (Eds.), The nature of vocabulary acquisition (pp. 19-35). New York: Lawrence Erlbaum Associates.

Navarrete, E., Mahon, B. Z., \& Caramazza, A. (2010). The cumulative semantic cost does not reflect lexical selection by competition. Acta Psychologica, 134(3), 279-89. http://doi.org/10.1016/j.actpsy.2010.02.009

Oppenheim, G. M., Barr, P., \& Tainturier, M. J. (2016). Preserved cumulative semantic interference despite explicit memory impairment. In Proceedings of the 2016 International Meeting of the Psychonomic Society. Granada, Spain.

Oppenheim, G. M., Dell, G. S., \& Schwartz, M. F. (2007). Cumulative semantic interference as learning. Brain and Language, 103(1-2), 175-176. http://doi.org/10.1016/j.bandl.2007.07.102

Oppenheim, G. M., Dell, G. S., \& Schwartz, M. F. (2010). The dark side of incremental learning: a model of cumulative semantic interference during lexical access in speech production. Cognition, 114(2), 227-252. http://doi.org/10.1016/j.cognition.2009.09.007

Rabbitt, P. M. A. (1966). Errors and error correction in choice-response tasks. Journal of Experimental Psychology, 71(2), 264-272. http://doi.org/10.1037/h0022853

Roelofs, A. (2018). A unified computational account of cumulative semantic, semantic blocking, and semantic distractor effects in picture naming. Cognition, 172(May 2017), 59-72. http://doi.org/10.1016/j.cognition.2017.12.007

Tamminen, J., \& Gaskell, M. G. (2013). Novel word integration in the mental lexicon: Evidence from unmasked and masked semantic priming. The Quarterly Journal of Experimental Psychology, 66(5), 1001-1025. http://doi.org/10.1080/17470218.2012.724694 
Tyler, M. D., Tyler, L., \& Burnham, D. K. (2005). The delayed trigger voice key: an improved analogue voice key for psycholinguistic research. Behavior Research Methods, 37(1), 13947.

van der Ven, F., Takashima, A., Segers, E., \& Verhoeven, L. (2015). Learning Word Meanings: Overnight Integration and Study Modality Effects. Plos One, 10(5), e0124926. http://doi.org/10.1371/journal.pone.0124926

van Heuven, W. J. B., Mandera, P., Keuleers, E., \& Brysbaert, M. (2013). Subtlex-UK: A new and improved word frequency database for British English. The Quarterly Journal of Experimental Psychology, 1-36. http://doi.org/10.1080/17470218.2013.850521 


\section{Appendix A.}

Participants' novelty ratings confirmed that most novel exemplars were completely novel. Any novel item that a participant rated as less than completely novel was discarded from their data, pending one check: because a few participants voiced concern over having misentered a rating (e.g. rating forehead as completely novel, and yapok as mundane), I calculated each participant's mean Session 1 accuracy for the items that they had confirmed as completely novel, and retained the few rated-non-novel participant-items whose Session 1 accuracy was at or below this level.

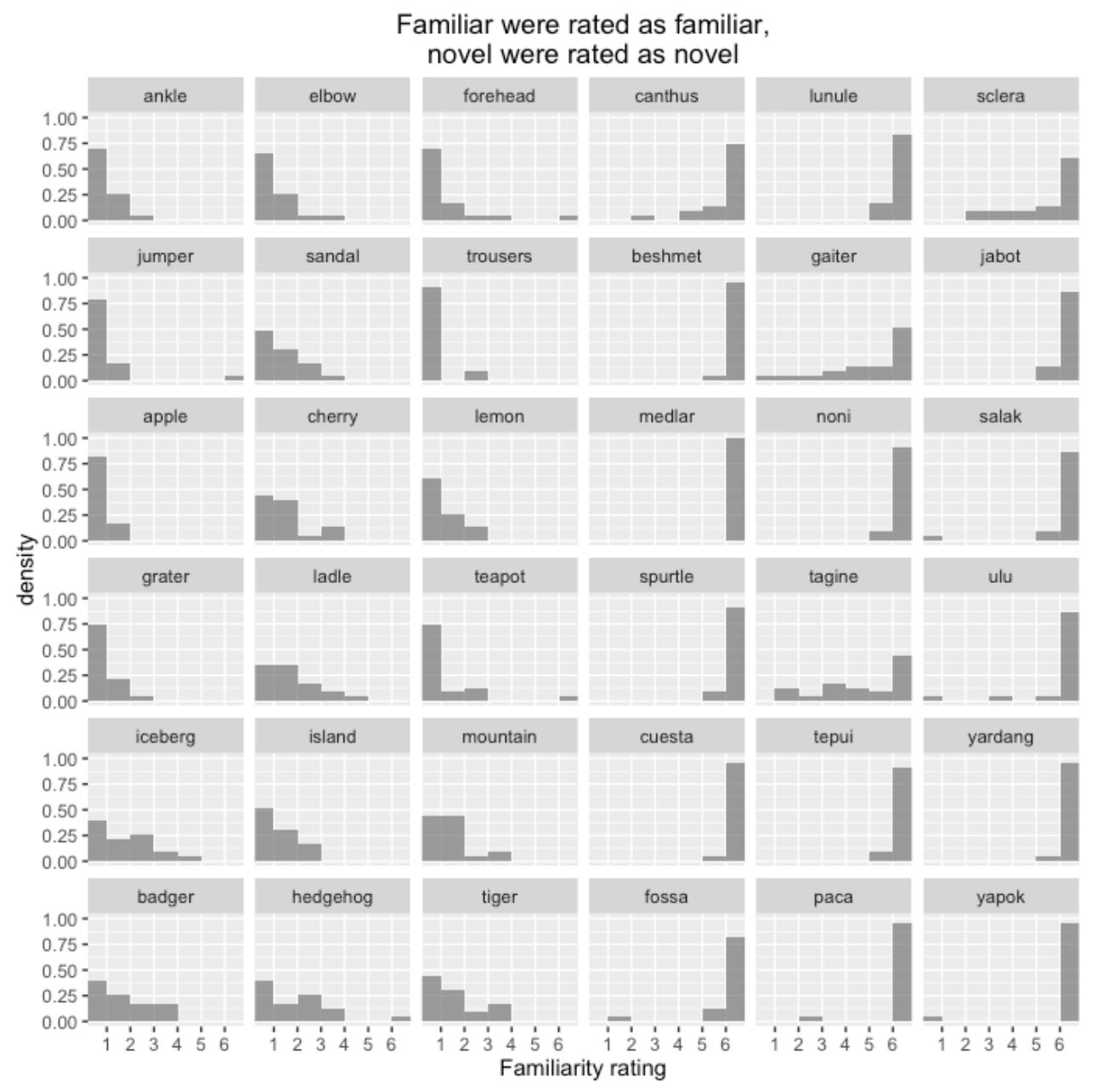




\section{Appendix B.}

Summary of naming errors and exclusions. These are reported as count data, allowing readers to calculate proportions or odds according to their interests. Interruptions are coded as semantic or nonsemantic if they match exactly one completed word error for the same target.

'Mispronunciations' include any idiolect-inconsistent pronunciations, including meaning-driven blends. RTs for trials with voicekey errors were excluded if they caused the voicekey to trigger early, thus displaying the picture name. RTs for correct responses that followed an error trial were excluded, lest they create spurious RT effects via post-error slowing.

\begin{tabular}{lrrrrrr}
\hline & \multicolumn{2}{c}{ Familiar } & & \multicolumn{2}{c}{ Novel } \\
\cline { 2 - 3 } \cline { 5 - 6 } & Session 1 & Session 2 & & Session 1 & Session 2 \\
\hline Correct & 1698 & 1861 & & 1298 & 1633 \\
\hline All errors & 19 & 21 & & 312 & 60 \\
Same category word & 8 & 7 & & 94 & 28 \\
Complete & 4 & 2 & 60 & 14 \\
Incomplete & 4 & 5 & 34 & 14 \\
Different category word & 0 & 1 & & 18 & 4 \\
Complete & 0 & 1 & & 10 & 2 \\
Incomplete & 0 & 0 & & 2 \\
Omission & 0 & 1 & 75 & 7 \\
Mispronunciation & 2 & 1 & 53 & 6 \\
Miscellaneous & 9 & 11 & & 71 & 15 \\
\hline Voicekey error & 26 & 6 & & 15 & 7 \\
Correct, post-error & 201 & 56 & 103 & 28 \\
Non-novel item & 0 & 0 & 216 & 216 \\
\hline
\end{tabular}


Logistic regression of combined lexical, phonological, miscellaneous, and omission errors for novel word targets.

\begin{tabular}{lrrrr}
\hline & Coef $\beta$ & $\mathrm{SE}(\beta)$ & $\mathbf{p}$ & $\mathrm{OR}(\exp (\beta))$ \\
\hline ((Intercept)) & -3.21 & 0.37 & $<. \mathbf{0 0 1}$ & 0.04 \\
myCenter(Session) & -2.10 & 0.17 & $<. \mathbf{0 0 1}$ & 0.12 \\
myCenter(Repetition) & -0.28 & 0.05 & $<. \mathbf{0 0 1}$ & 0.76 \\
myCenter(TrialInSubCycle) & 0.06 & 0.05 & 0.19 & 1.06 \\
myCenter(PrevCompCountSameSubset) & 0.25 & 0.10 & $\mathbf{0 . 0 1 5}$ & 1.28 \\
myCenter(PrevCompCountDiffSubset) & 0.01 & 0.06 & 0.87 & 1.01 \\
myCenter(Session):myCenter(Repetition) & 0.18 & 0.09 & $\mathbf{0 . 0 4 7}$ & 1.20 \\
myCenter(Session):myCenter(TrialInSubCycle) & -0.07 & 0.09 & 0.43 & 0.93 \\
myCenter(Session):myCenter(PrevCompCountSameSubset) & 0.25 & 0.20 & 0.21 & 1.28 \\
myCenter(Session):myCenter(PrevCompCountDiffSubset) & -0.04 & 0.13 & 0.77 & 0.96 \\
\hline
\end{tabular}




\section{Appendix C.}

Main linear mixed effects regression of inverse-transformed $(100000 *-1 /$ RT $)$ naming latencies show immediate and stable cumulative semantic interference between and among both familiar and novel category members. Betas describe inverse-transformed RT effect sizes at the experiment grand mean RT. The -1 in the transformation means that the positive/negative valence is consistent with that for untransformed RTs. Effect sizes in milliseconds can be estimated by adding the relevant components and backtransforming. For example the grand mean is computed as:

$$
\frac{-100000}{(\text { Intercept })}=\frac{-100000}{-146.503}=682.5799 \mathrm{~ms}
$$

Similarly, the main effect of Novelty is:

\begin{tabular}{|c|c|c|c|c|}
\hline & Coef $\beta$ & Lower $(\beta)$ & Upper $(\beta)$ & $p$ \\
\hline (Intercept) & -146.503 & -152.477 & -140.530 & - \\
\hline Session $(1,2)$ & -8.202 & -12.090 & -4.315 & $<.001$ \\
\hline Novelty (familiar, novel) & 38.637 & 29.865 & 47.409 & $<.001$ \\
\hline Cycle $(1: 6)$ & -0.645 & -1.313 & 0.023 & 0.058 \\
\hline Trial in subcycle $(1: 6)$ & -0.285 & -0.659 & 0.089 & 0.14 \\
\hline Ordinal position ${ }_{\text {within Novelty }}(1: 3)$ & 2.324 & 1.492 & 3.156 & $<.001$ \\
\hline Ordinal position between Novelty $(0: 3)$ & 1.610 & 1.172 & 2.047 & $<.001$ \\
\hline Session $\times$ Novelty (familiar, novel) & -15.734 & -19.652 & -11.816 & $<.001$ \\
\hline Session $\times$ Cycle & 0.220 & -0.694 & 1.135 & 0.64 \\
\hline Session $\times$ Trial in subcycle & -0.061 & -0.770 & 0.647 & 0.87 \\
\hline Session $\times$ Ordinal position $_{\text {within Novelty }}$ & 0.611 & -0.646 & 1.867 & 0.34 \\
\hline Session $\times$ Ordinal position between Novelty & -0.232 & -1.044 & 0.579 & 0.57 \\
\hline Novelty $\times$ Cycle & -2.591 & -3.176 & -2.006 & $<.001$ \\
\hline Novelty $\times$ Trial in subcycle & -0.182 & -1.000 & 0.636 & 0.66 \\
\hline Novelty $\times$ Ordinal position within Novelty & 0.257 & -1.126 & 1.639 & 0.72 \\
\hline Novelty $\times$ Ordinal position between Novelty & 0.846 & -0.032 & 1.724 & 0.059 \\
\hline Session $\times$ Novelty $\times$ Cycle & 0.248 & -0.947 & 1.443 & 0.68 \\
\hline Session $\times$ Novelty $\times$ Trial in subcycle & -0.166 & -1.396 & 1.064 & 0.79 \\
\hline Session $\times$ Novelty $\times$ Ordinal position ${ }_{\text {within Novelty }}$ & -1.294 & -3.902 & 1.315 & 0.33 \\
\hline Session $\times$ Novelty $\times$ Ordinal position between Novelty & 0.069 & -1.561 & 1.699 & 0.93 \\
\hline
\end{tabular}

$$
\begin{aligned}
& \frac{-100000}{(\text { Intercept })+0.5 * \beta_{\text {Novelty }}}-\frac{-100000}{(\text { Intercept })-0.5 * \beta_{\text {Novelty }}} \\
& =\frac{-100000}{-146.503+.5 * 38.637}-\frac{-100000}{-146.503-.5 * 38.637} \\
& =786.2593-603.0581=183.2012 \mathrm{~ms}
\end{aligned}
$$


Restricted to just the Session 1 data:

\begin{tabular}{|c|c|c|c|c|}
\hline & Coef $\beta$ & Lower $(\beta)$ & Upper $(\beta)$ & $p$ \\
\hline (Intercept) & -142.834 & -149.034 & -136.634 & - \\
\hline Novelty (familiar, novel) & 46.640 & 36.997 & 56.283 & $<.001$ \\
\hline Cycle (1:6) & -0.767 & -1.710 & 0.176 & 0.11 \\
\hline Trial in subcycle (1:6) & -0.376 & -0.905 & 0.153 & 0.16 \\
\hline Ordinal position within Novelty $_{(1: 3)}$ & 2.134 & 1.115 & 3.152 & $<.001$ \\
\hline Ordinal position between Novelty $(0: 3)$ & 1.724 & 0.970 & 2.479 & $<.001$ \\
\hline Novelty $\times$ Cycle & -2.767 & -3.702 & -1.833 & $<.001$ \\
\hline Novelty $\times$ Trial in subcycle & 0.026 & -1.131 & 1.183 & 0.97 \\
\hline Novelty $\times$ Ordinal position within Novelty & 0.936 & -1.042 & 2.914 & 0.35 \\
\hline Novelty $\times$ Ordinal position ${ }_{\text {between Novelty }}$ & 0.922 & -0.592 & 2.436 & 0.23 \\
\hline
\end{tabular}

Restricted to just the Session 2 data:

\begin{tabular}{|c|c|c|c|c|}
\hline & Coef $\beta$ & Lower $(\beta)$ & Upper $(\beta)$ & $p$ \\
\hline (Intercept) & -149.873 & -156.176 & -143.571 & - \\
\hline Novelty (familiar, novel) & 31.660 & 23.274 & 40.046 & $<.001$ \\
\hline Cycle $(1: 6)$ & -0.482 & -1.198 & 0.234 & 0.19 \\
\hline Trial in subcycle $(1: 6)$ & -0.406 & -0.863 & 0.050 & 0.081 \\
\hline Ordinal position $_{\text {within Novelty }}(1: 3)$ & 2.465 & 1.478 & 3.452 & $<.001$ \\
\hline Ordinal position between Novelty $(0: 3)$ & 1.470 & 0.943 & 1.997 & $<.001$ \\
\hline Novelty $\times$ Cycle & -2.476 & -3.216 & -1.737 & $<.001$ \\
\hline Novelty $\times$ Trial in subcycle & -0.174 & -1.148 & 0.799 & 0.73 \\
\hline Novelty $\times$ Ordinal position within Novelty & -0.320 & -2.255 & 1.615 & 0.75 \\
\hline Novelty $\times$ Ordinal position between Novelty & 0.796 & -0.260 & 1.852 & 0.14 \\
\hline
\end{tabular}




\section{Restricted to just the Novel words:}

\section{Just New items}

\begin{tabular}{|c|c|c|c|c|}
\hline & Coef $\beta$ & Lower $(\beta)$ & Upper $(\beta)$ & $p$ \\
\hline (Intercept) & -125.969 & -133.672 & -118.265 & - \\
\hline Session $(1,2)$ & -17.109 & -21.189 & -13.030 & $<.001$ \\
\hline Cycle $(1: 6)$ & -1.930 & -2.601 & -1.260 & $<.001$ \\
\hline Trial in subcycle $(1: 6)$ & -0.336 & -1.088 & 0.415 & 0.38 \\
\hline Ordinal position $_{\text {within Novelty }}(1: 3)$ & 2.490 & 1.584 & 3.397 & $<.001$ \\
\hline Ordinal position between Novelty $(0: 3)$ & 2.041 & 1.464 & 2.617 & $<.001$ \\
\hline Session $\times$ Cycle & 0.495 & -0.334 & 1.323 & 0.24 \\
\hline Session $\times$ Trial in subcycle & -0.391 & -1.436 & 0.654 & 0.46 \\
\hline Session $\times$ Ordinal position $_{\text {within Novelty }}$ & -0.482 & -2.290 & 1.326 & 0.6 \\
\hline Session $\times$ Ordinal position ${ }_{\text {between Novelty }}$ & -0.195 & -1.356 & 0.967 & 0.74 \\
\hline
\end{tabular}

Just New items in Session 1

\begin{tabular}{lrrrl}
\hline & Coef $\beta$ & Lower $(\beta)$ & Upper $(\beta)$ & \multicolumn{1}{c}{$p$} \\
\hline Intercept) & -116.630 & -124.876 & -108.384 & - \\
Cycle (1:6) & -2.215 & -3.084 & -1.346 & $<.001$ \\
Trial in subcycle (1:6) & -0.316 & -1.140 & 0.509 & 0.45 \\
Ordinal position $_{\text {within Novelty }}(1: 3)$ & 2.660 & 1.202 & 4.118 & $<.001$ \\
Ordinal position $_{\text {between Novelty }}(0: 3)$ & 2.187 & 1.250 & 3.123 & $<.001$ \\
\hline
\end{tabular}

Just New items in Session 2

\begin{tabular}{lrrrl}
\hline & Coef $\beta$ & Lower $(\beta)$ & Upper $(\beta)$ & \multicolumn{1}{c}{$p$} \\
\hline (Intercept) & -133.466 & -141.161 & -125.771 & - \\
Cycle (1:6) & -1.727 & -2.435 & -1.019 & $<.001$ \\
Trial in subcycle (1:6) & -0.500 & -1.317 & 0.317 & 0.23 \\
Ordinal position $_{\text {within Novelty }}(1: 3)$ & 2.419 & 1.061 & 3.778 & $<.001$ \\
Ordinal position $_{\text {between Novelty }}(0: 3)$ & 1.942 & 1.221 & 2.662 & $<.001$ \\
\hline
\end{tabular}


Restricted to just the Familiar words:

\section{Just Old items}

\begin{tabular}{lrrrl}
\hline & Coef $\beta$ & Lower $(\beta)$ & Upper $(\beta)$ & $p$ \\
\hline Intercept) & -164.032 & -171.002 & -157.062 & - \\
Session (1,2) & -1.068 & -5.602 & 3.467 & 0.64 \\
Cycle (1:6) & 0.578 & -0.175 & 1.331 & 0.13 \\
Trial in subcycle (1:6) & -0.352 & -0.756 & 0.052 & 0.088 \\
Ordinal position $_{\text {within Novelty }}(1: 3)$ & 2.092 & 0.777 & 3.406 & $\mathbf{0 . 0 0 2}$ \\
Ordinal position $_{\text {between Novelty }}(0: 3)$ & 1.138 & 0.425 & 1.850 & $\mathbf{0 . 0 0 2}$ \\
Session $\times$ Cycle $_{\text {Session } \times \text { Trial in subcycle }}$ & 0.084 & -1.166 & 1.333 & 0.9 \\
Session $\times$ Ordinal position $_{\text {within Novelty }}$ & 0.133 & -0.702 & 0.969 & 0.75 \\
Session $\times$ Ordinal position $_{\text {between Novelty }}$ & -0.875 & -0.885 & 2.635 & 0.33 \\
\hline
\end{tabular}

Just Old items in Session 1

\begin{tabular}{lrrrl}
\hline & Coef $\beta$ & Lower $(\beta)$ & Upper $(\beta)$ & $p$ \\
\hline (Intercept) & -163.192 & -170.499 & -155.885 & - \\
Cycle (1:6) & 0.475 & -0.650 & 1.599 & 0.41 \\
Trial in subcycle (1:6) & -0.421 & -1.059 & 0.217 & 0.2 \\
Ordinal position $_{\text {within Novelty }}(1: 3)$ & 1.689 & 0.055 & 3.322 & $\mathbf{0 . 0 4 3}$ \\
Ordinal position $_{\text {between Novelty }}(0: 3)$ & 1.326 & 0.223 & 2.428 & $\mathbf{0 . 0 1 8}$ \\
\hline
\end{tabular}

Just Old items in Session 2

\begin{tabular}{lrrrl}
\hline & Coef $\beta$ & Lower $(\beta)$ & Upper $(\beta)$ & $p$ \\
\hline Intercept) & -164.638 & -172.003 & -157.273 & - \\
Cycle (1:6) & 0.631 & -0.237 & 1.498 & 0.15 \\
Trial in subcycle (1:6) & -0.311 & -0.869 & 0.246 & 0.27 \\
Ordinal position $_{\text {within Novelty }}(1: 3)$ & 2.675 & 1.356 & 3.994 & $<.001$ \\
Ordinal position $_{\text {between Novelty }}(0: 3)$ & 1.041 & 0.199 & 1.883 & $\mathbf{0 . 0 1 5}$ \\
\hline
\end{tabular}

